\title{
New frontiers in immunosuppression
}

\author{
Luke J. Benvenuto, Michaela R. Anderson, Selim M. Arcasoy \\ Division of Pulmonary, Allergy and Critical Care Medicine, Department of Medicine, Columbia University Medical Center, New York, USA \\ Contributions: (I) Conception and design: All authors; (II) Administrative support: All authors; (III) Provision of study materials or patients: All \\ authors; (IV) Collection and assembly of data: All authors; (V) Data analysis and interpretation: All authors; (VI) Manuscript writing: All authors; (VII) \\ Final approval of manuscript: All authors. \\ Correspondence to: Selim M. Arcasoy. Division of Pulmonary, Allergy and Critical Care Medicine, Department of Medicine, Columbia University \\ Medical Center, 622 West 168th Street, PH-14 Room 104, New York, NY 10032, USA. Email: sa2059@cumc.columbia.edu.
}

\begin{abstract}
Immunosuppressive therapy is arguably the most important component of medical care after lung transplantation. The goal of immunosuppression is to prevent acute and chronic rejection while maximizing patient survival and long-term allograft function. However, the benefits of immunosuppressive therapy must be balanced against the side effects and major toxicities of these medications. Immunosuppressive agents can be classified as induction agents, maintenance therapies, treatments for acute rejection and chronic rejection and antibody directed therapies. Although induction therapy remains an area of controversy in lung transplantation, it is still used in the majority of transplant centers. On the other hand, maintenance immunosuppression is less contentious; but, unfortunately, since the creation of three-drug combination therapy, including a glucocorticoid, calcineurin inhibitor and anti-metabolite, there have been relatively modest improvements in chronic maintenance immunosuppressive regimens. The presence of HLA antibodies in transplant candidates and development of de novo antibodies after transplantation remain a major therapeutic challenge before and after lung transplantation. In this chapter we review the medications used for induction and maintenance immunosuppression along with their efficacy and side effect profiles. We also review strategies and evidence for HLA desensitization prior to lung transplantation and management of de novo antibody formation after transplant. Finally, we review immune tolerance and the future of lung transplantation to limit the toxicities of conventional immunosuppressive therapy.
\end{abstract}

Keywords: Induction; maintenance; immunosuppression; desensitization; immune tolerance

Submitted Oct 24, 2017. Accepted for publication Mar 21, 2018.

doi: $10.21037 /$ jtd.2018.04.79

View this article at: http://dx.doi.org/10.21037/jtd.2018.04.79

\section{Introduction}

Early immunosuppression strategies after solid organ transplantation included total body irradiation, cyclophosphamide, and methotrexate (1). Predictably, myeloablative therapy prior to solid organ transplant led to major complications related to the treatment rather than rejection (1). With the discovery of 6-mercaptopurine/ azathioprine, kidney transplantation outcomes became more successful in the 1960's, and work by Dr. Thomas Starzl and others demonstrated the effectiveness of combination immunosuppressive therapy for maintaining prolonged graft survival (1-3). Unfortunately, advances in lung transplantation did not occur as quickly after Dr. James Hardy performed the first lung transplantation in the United States in 1963 (4). It was not until the advent of cyclosporine that lung transplantation began to experience prolonged graft survival (5).

\section{Induction therapy}

The first lung transplant surgeries of the modern era were performed without the use of induction therapy (6). Unfortunately, early survival remained poor with a median survival of 3.0 years from 1988 to 1991, a survival rate 
which, by the turn of the century had not significantly changed (7). Recipients were plagued by high rates of early acute cellular rejection (ACR) and bronchiolitis obliterans syndrome (BOS), or late allograft failure $(7,8)$. ACR is attributed to immune stimulation mediated by host T-cells infiltrating the allograft after activation by MHC-presentation of foreign donor antigens. The risk of ACR in the early post-transplant period may be further increased by changes in antigen presentation associated with organ retrieval and processing (9). In order to target this T-cell mediated process, some centers proposed the use of induction therapy to deplete lymphocyte stores, disrupt T-cell function and induce immune tolerance $(10,11)$. This reflected similar practices in cardiac (12) and renal transplantation (13). Supporters cited the additional possibility that early induction would reduce the required doses of nephrotoxic calcineurin inhibitors in the early post-transplant period (14). Critics were concerned about the risks of compromising systemic immunity and consequently increasing rates of infection and malignancy, both of which had been reported in other solid organ transplants $(15,16)$.

While the debate over the risks and benefits of induction therapy continues, induction therapy use has increased. Induction therapy was utilized in approximately $50 \%$ of lung transplants in 2004 as compared to its use in greater than $70 \%$ of lung transplants in the first half of 2016 (17-19). Despite nearly 20 years since the first use of induction therapy, its role in lung transplantation has not been rigorously studied. A 2013 meta-analysis found only three randomized clinical trials directly addressing this question (total $\mathrm{n}=140$ ) and demonstrated no significant difference in mortality, ACR grade 2 or higher, or BOS, though cumulative hazard ratios trended in favor of induction therapy (20). A recent retrospective analysis of the United Network for Organ Sharing (UNOS) database including more than 6,000 subjects demonstrated significantly improved survival for subjects receiving alemtuzumab or basiliximab compared to no induction therapy (21). Perhaps the tides are finally turning.

The three induction agents currently in use are polyclonal anti-thymocyte globulin (ATG), anti-CD52 monoclonal antibody (alemtuzumab) and interleukin-2 (IL-2) receptor antagonists (basiliximab). Since 2004 more than $80 \%$ of induction therapy recipients received IL-2 receptor antagonists, a continued trend upward from approximately $40 \%$ in $2006(19)$.
$A T G$

ATG is composed of polyclonal immunoglobulins derived from either horse or rabbit exposure to human thymocytes. The resulting polyclonal immunoglobulins are directed at multiple different human lymphocyte antigens. Immunoglobulin binding leads to complementmediated lymphocyte cell lysis, antibody-mediated cell lysis, macrophage-mediated phagocytosis and lymphocyte opsonization followed by removal through the reticuloendothelial system (22). Induction doses of ATG vary based on the given formulation (rabbit vs. equine) but are administered for 3 consecutive days following transplantation (10). Lymphocyte depletion may last as long as 6-8 months (23).

One of the major concerns regarding ATG use is the possibility of an acute cytokine storm in response to ATG infusion. Subjects may develop non-cardiogenic pulmonary edema, chest pain and shortness of breath. Milder syndromes have also been reported including a serum sickness-like illness with diffuse rash, fever, pruritus, myalgia and arthralgia. Serum sickness may occur days to weeks after infusion. A majority of ATG-treated patients will develop anti-rabbit or anti-equine antibodies (24) which may complicate subsequent ATG dosing. Additionally, thymoglobulin is a treatment option for high grade and/or refractory acute rejection (25) thus prior exposure to ATG may theoretically complicate subsequent use though there is no available literature to support this.

\section{Alemtuzumab}

Alemtuzumab is a monoclonal antibody directed against the cell surface marker CD52. CD52 is expressed on the surface of B-cells, T-cells, monocytes, macrophages, and NK cells (26). Alemtuzumab binds to this cell surface protein leading to complement-mediated cytolysis, antibodymediated cytotoxicity and programmed cell death. Alemtuzumab is dosed at $30 \mathrm{mg}$ IV prior to reperfusion or immediately following transplantation $(27,28)$. Alemtuzumab has a 12-day half-life; however cell function is impaired significantly longer with monocyte, B-cell and T-cell recovery at 3, 6 and 12 months respectively (29).

Given the prolonged lymphopenia associated with alemtuzumab therapy, there is significant concern regarding risk of infection and post-transplant lymphoproliferative disease (PTLD). Recent work has been limited to single center and large registry studies and the results have been 
Table 1 Review of induction therapies

\begin{tabular}{|c|c|c|c|c|}
\hline Agent & $\begin{array}{l}\text { Formulations (brand } \\
\text { name) }\end{array}$ & Mechanism of action & Side effects & $\begin{array}{l}\text { Percent of } \\
\text { transplant centers } \\
\text { using for induction* }\end{array}$ \\
\hline Anti-CD52 & $\begin{array}{l}\text { Alemtuzumab } \\
\text { (Campath) }\end{array}$ & $\begin{array}{l}\text { Binds to CD52, expressed by B cells, T-cells, } \\
\text { NK cells, monocytes and leads to cell lysis, } \\
\text { prolonged leukocyte depletion ( } 26)\end{array}$ & $\begin{array}{l}\text { Cytokine storm; } \\
\text { prolonged } \\
\text { lymphopenia (29) }\end{array}$ & $11 \%(19)$ \\
\hline
\end{tabular}

*, values indicate rates of use among recipients who received induction therapy between 2004 and 2016, according to the 2017 report of the International Society for Heart and Lung Transplantation (19). ATG, anti-thymocyte globulin.

heterogeneous with multiple single center studies showing no significant difference in rates of infection $(27,30)$ or PTLD (28) between alemtuzumab and basiliximab groups, while the UNOS registry analysis demonstrated increased rates of non-CMV infection and PTLD following the use of alemtuzumab compared to either basiliximab or no induction therapy (21).

\section{$I L-2$ receptor antagonists}

IL-2 receptor antagonists are chimeric antibodies (mouse + human) directed against the alpha subunit of the CD25 cell surface protein (the IL-2 receptor). Basiliximab is currently in use within the US, while daclizumab is no longer on the market due to decreased demand. These IL-2 receptor antagonists bind to the IL-2 receptor and block IL-2 dependent signaling. T-cells rely on IL-2 signaling for proliferation and differentiation thus IL-2 receptor antagonists inhibit this process. Unlike the other induction agents however, IL-2 receptor antagonists do not lead to cell death or significant T-cell depletion. Basiliximab is dosed at $20 \mathrm{mg}$ at time 0 and 4 days after transplantation based on literature demonstrating increased rates of ACR if the first dose is given post-transplantation (31) mirroring findings seen in pediatric heart transplantation (32). Basiliximab has a half-life of 7.2 \pm 3.2 days (Basiliximab drug insert) but may block the receptor for up to $59 \pm 17$ days when combined with triple drug therapy consisting of cyclosporine, prednisone and mycophenolate mofetil (Basiliximab drug insert). Basiliximab is a humanized antibody and thus not associated with the infusion reactions observed during ATG and alemtuzumab treatment.

\section{Outcomes with induction therapy}

There are limited randomized controlled trials comparing no induction, ATG, alemtuzumab and basiliximab, and hence clinical practice is based largely on observational studies, large registry analyses and center preference (Table 1). Compared to no induction, ATG has been associated with decreased rates of ACR, increased malignancy, a trend towards increased $\mathrm{CMV}$ infection and no significant difference in BOS or overall graft survival $(10,33)$. Compared to historical controls who did not receive induction, the IL-2 receptor antagonists have been associated with decreased early ACR $(34,35)$ without increased incidence of infection or malignancy while alemtuzumab use as induction therapy has revealed more conflicting results. One large retrospective analysis showed significantly fewer episodes of ACR, greater freedom from BOS, increased overall survival with significantly fewer deaths from graft failure and a trend towards increased risk of PTLD with alemtuzumab compared to no induction (28). However, another smaller study using historical controls demonstrated no significant difference in ACR, survival or infection rates (36). Notably both studies reported reduced dose maintenance immunosuppression post-transplantation among subjects using alemtuzumab, further emphasizing the potential effectiveness of this therapy.

In head to head studies, alemtuzumab or basiliximab may be associated with lower rates of ACR and improved overall survival compared to ATG preparations $(20,27,37)$; 
though only alemtuzumab has been demonstrated to offer the additional benefit of decreased maintenance immunosuppression (38). A recent analysis of the UNOS national registry demonstrated increased survival free of BOS for subjects receiving alemtuzumab compared to basiliximab (21). Inherent in this analysis were the challenges of large observational datasets including significant differences between groups. Nonetheless, smaller observational studies have revealed similar findings $(28,30)$. Ongoing concerns regarding the risk of prolonged lymphocyte depletion associated with alemtuzumab therapy, combined with the relatively mild side effect profile of basiliximab likely account for the growing prevalence of basiliximab use although studies addressing this question have demonstrated mixed results $(11,21,30)$. Additional randomized controlled trials comparing rates of ACR, BOS, infection and PTLD between alemtuzumab and basiliximab are certainly warranted.

While the use of induction immunosuppression is not yet universal in lung transplantation, it is becoming increasingly common. The preponderance of evidence suggests that it is associated with lower rates of ACR and improved overall survival. Nonetheless, it is prudent for all centers to continue to consider the possibility of increased infectious and malignant complications associated with the use of some induction therapies. Further research is required to identify the optimal therapy choice and the patient population that is most likely to benefit from induction therapy.

\section{Maintenance immunosuppression}

Maintenance immunosuppressive therapy is arguably the most important part of medical care after lung transplantation, and its main purpose is to prevent acute and chronic rejection. However, this goal must be balanced with side effects and major toxicities associated with these medications. Maintenance immunosuppressive regimens for lung transplantation are largely extrapolated from observational studies and trials in renal, liver and heart transplantation $(22,39)$. Protocols for maintenance immunosuppressive regimens vary among lung transplant centers, but typical regimens consist of a three-drug combination including a calcineurin inhibitor, an anti-metabolite and a glucocorticoid (39-42). Combination regimens allow for higher levels of immunosuppression while also minimizing the toxicities of an individual medication (22). Due to higher rates of ACR in the early post-transplant course, transplant protocols typically utilize greater intensity of immunosuppression in the first year after transplant (43). Naturally, this potential benefit of higher intensity of immunosuppressive treatment must be balanced against the adverse effects of overimmunosuppression including greater susceptibility to infection (44) and malignancy (45).

\section{Glucocorticoids}

Glucocorticoids are a mainstay of immunosuppressive regimens after lung transplantation because they have widespread inhibitory effects on the immune system and act through a variety of signaling pathways (46). Glucocorticoids bind to the intracellular glucocorticoid receptor generating a complex that blocks the transcription of inflammatory cytokines mainly through an interaction with nuclear factorkappa-B (NF-KB), but also through the induction of antiinflammatory proteins such as annexin-1 and MAPK phosphatase-1 (46). Through these pathways glucocorticoids inhibit macrophage activation and reduce lymphocyte proliferation and migration (47). Glucocorticoids are certainly not without side effects; long term glucocorticoid use can lead to infectious complications, osteoporosis, diabetes, hyperlipidemia, cataracts, psychiatric and mood changes, weight gain, myopathy, hypertension and impaired wound healing $(48,49)$. Fortunately, these risks are dose dependent and can be somewhat mitigated by reduced dosages (50). Prednisone is the classic glucocorticoid used after lung transplant; usually after an induction dose, it is reduced to $0.5 \mathrm{mg} / \mathrm{kg} /$ day in the immediate post-transplant period followed by a reduction over the next several months to a dose of $5-10 \mathrm{mg}$ for maintenance treatment $(39,41)$. Total glucocorticoid withdrawal is rare (42); a few small studies have reported varying success after withdrawal $(51,52)$.

\section{Calcineurin inbibitors}

Cyclosporine was originally isolated from the fungus, Tolypocladium inflatum, and its identification as an immunosuppressant agent revolutionized solid organ transplantation (41). After the discovery of cyclosporine, the field of lung transplantation started to demonstrate notable success (5). Cyclosporine binds cyclophilins present inside cells forming a drug-receptor complex that competitively binds and inhibits calcineurin, a calcium and calmodulin-dependent protein phosphatase, resulting in the inhibition of nuclear factor of activated T-cells (NFAT) related transcription factors (53). This leads to reduced transcriptional activation of cytokines IL-2, tumor necrosis 
factor- $\alpha$, IL-3, IL-4, CD40L, granulocyte-macrophage colony stimulating factor, and interferon- $\gamma$, thereby reducing T-cell activation and proliferation (54).

Cyclosporine is available in an unmodified and modified form. The unmodified form is an oil-based emulsion that has unreliable absorption (Sandimmune, Novartis Pharmaceuticals Corp.). The unmodified preparation has largely been replaced by the modified form (Neoral, Novartis Pharmaceuticals Corp.) which provides greater bioavailability and more predictable absorption $(39,41)$. Careful therapeutic monitoring is needed to ensure efficacy and avoid toxicity. Measurements of area under the curve (AUC) have shown some superiority for cyclosporine level monitoring with reduced ACR and lower nephrotoxicity in renal transplant (55). However, determining the AUC involves multiple measurements and as a result it is quite difficult and not practical $(39,41,56)$. Other options include measuring levels 2 hours after the dose (C2) or trough levels (C0). Studies have suggested that C2 monitoring is more closely correlated with AUC and may reduce nephrotoxicity compared with $\mathrm{C} 0$ monitoring $(57,58)$. Target cyclosporine levels are dependent on the time from transplant and center specific protocols, but generally target $\mathrm{C} 0$ levels range from $100-450 \mathrm{ng} / \mathrm{mL}$ and C2 levels range from $800-1,400 \mathrm{ng} / \mathrm{mL}$ $(39,41)$. Nephrotoxicity, both acute and chronic, is the principal side effect of cyclosporine and can be mitigated by reducing the target level (59). Other side effects include hirsutism, gingival hyperplasia, neurotoxicity such as seizures and tremors, hypertension, diabetes, and dyslipidemia (60-65).

Tacrolimus is another calcineurin inhibitor that was first identified in a soil sample in 1984 and became available for clinical use in 1994 after demonstrating efficacy in renal and liver transplantation and as a rescue medication in the setting of rejection (66). Tacrolimus binds to intracellular FKBP12, also forming a drug receptor complex that competitively binds with calcineurin and acts through the same pathway as cyclosporine to inhibit T-cell activation and proliferation (53). Tacrolimus is considerably more potent than cyclosporine and has oral bioavailability of around $20-25 \%$ (67). Transplant centers typically monitor trough levels despite studies that have demonstrated that post dose levels are a better predictor of AUC $(68,69)$. Target trough levels for tacrolimus range between 5 and 15 depending on comorbidities, time from transplant and center specific protocols $(39,41)$. The side effect profile for tacrolimus is similar to cyclosporine with less hypertension (65) and hyperlipidemia (64) but more neurotoxicity $(70,71)$ and diabetes (64). Both tacrolimus and cyclosporine are metabolized through the CYP450 3A4 pathway, and careful attention with dose adjustment is needed when using medications that induce or inhibit these enzymes (69).

After clinical trials demonstrated the efficacy of tacrolimus in liver and kidney transplantation, Keenan et al. published the first randomized controlled trial in 1995 of 133 lung transplant recipients. They compared a regimen of tacrolimus, azathioprine and prednisone, with a regimen of cyclosporine, azathioprine, and prednisone and found similar ACR rates as well as survival rates, but less obliterative bronchiolitis (OB) on transbronchial biopsies (72). Subsequent trials by Zuckerman et al. $(73,74)$, Hachem et al. (75), and Treede et al. (76) reported variable results which are summarized in Table 2. In the largest randomized, multicenter study of 249 lung transplant recipients, Treede et al. demonstrated lower rates of BOS at 3 years in patients receiving a tacrolimus-based regimen compared with a cyclosporine-based regimen, $11.6 \%$ vs. $21.3 \%$, respectively $(\mathrm{P}=0.037)$ (76). Partially as a result of these studies as well as data from other solid organ transplantation, tacrolimus currently is the preferred calcineurin inhibitor and in 2016 it was used in over $90 \%$ of lung transplant recipients at the 1-year follow-up after transplant $(19,78)$.

\section{Antimetabolites}

Azathioprine was the first immunosuppressant in solid organ transplantation to be utilized in a multi-drug cocktail and has been in use in solid organ transplantation since the 1960's (1,79). Azathioprine is converted to 6-mercaptopurine (6-MP) and then into 6-thiouric acid, 6-methyl-MP and 6-thioguanine, ultimately acting as a nucleotide blocking agent and halting DNA replication (79). Azathioprine is usually dosed at 1 to $2 \mathrm{mg} / \mathrm{kg}$ daily with dose reductions made based on cell counts $(39,41)$. About $10 \%$ of the population has a thiopurine methyltransferase (TPMT) deficiency which is an important enzyme in azathioprine metabolism pathway. TPMT-deficient patients can develop severe myelosuppression due to azathioprine (79). Other side effects associated with azathioprine therapy include hepatotoxicity, cholestasis and pancreatitis $(39,79)$.

Mycophenolate is another antimetabolite; it has become the preferred anti-metabolite and in 2016, it was used in about $80 \%$ of lung transplant recipients at the 1-year follow-up after transplant $(19,78)$. Mycophenolate is also derived from fungi and is rapidly converted to its active form mycophenolic acid (MPA) in the liver. MPA inhibits 
Table 2 Tacrolimus vs. cyclosporine for lung transplant recipients

\begin{tabular}{|c|c|c|c|}
\hline Study & Population, $n$ & Methodology & Outcomes \\
\hline $\begin{array}{l}\text { Zuckerman } \\
\text { et al., } 2003 \\
(73,74,77)\end{array}$ & 74 & $\begin{array}{l}\text { Prospective, randomized, two center, } \\
\text { open label; comparing TAC/MMF/CS } \\
\text { vs. CsA/MMF/CS; at time of transplant, } \\
\text { mean follow-up } 507 \text { days; with later } \\
\text { follow-up of } 36 \text { months }\end{array}$ & $\begin{array}{l}\text { Survival: } 1 \text { year: } 71 \% \text { (TAC) vs. } 82 \%(C s A), P=N S \text {; survival: } \\
\text { 3-year: } 68 \% \text { (TAC) vs. } 57 \%(C s A), P=0.748 ; A R: 0.22 \text { (TAC) vs. } \\
0.32 \text { (CsA) AR episodes per } 100 \text { days, } P=0.097 ; \\
\text { Freedom from AR at } 1 \text { year: } 46 \%(T A C) \text { vs. } 35 \%(C s A), P=0.774 ; \\
\text { BOS incidence: } 10 \% \text { vs. } 41 \%, P<0.01\end{array}$ \\
\hline $\begin{array}{l}\text { Hachem, et al., } \\
2007 \text { (75) }\end{array}$ & 90 & $\begin{array}{l}\text { Prospective, randomized, single center, } \\
\text { open label; trial comparing TAC/ } \\
\text { AZA/CS vs. CsA/AZA/CS; at time of } \\
\text { transplant, median follow-up } 2.17 \text { years }\end{array}$ & $\begin{array}{l}\text { Composite end point: BOS 0p or cumulative acute rejection } \\
\text { score or A3 or higher or cumulative lymphocytic bronchiolitis of } \\
\text { B4 or higher; primary end point: } 54.5 \% \text { (TAC) vs. } 84.8 \% \text { (CsA), } \\
\text { P=0.002; freedom from BOS 0p: not different, } P=0.1\end{array}$ \\
\hline
\end{tabular}

AR, acute rejection; CsA, cyclosporine; TAC, tacrolimus; MMF, mycophenolate mofetil; AZA, azathioprine; CS, corticosteroids; NS, nonsignificant and not reported in article; OB, obliterative bronchiolitis on transbronchial biopsy; BOS, bronchiolitis obliterans syndrome; HR, hazard ratio.

inosine monophosphate dehydrogenase, the enzyme responsible for the synthesis of guanosine nucleotides, thereby halting DNA synthesis $(39,41,79)$. Uniquely, this is specific for $\mathrm{B}$ and $\mathrm{T}$-cell proliferation because most cells can access salvage pathways for guanosine nucleotide synthesis, whereas B- and T-cells rely solely on the inosine monophosphate pathway $(39,41,79)$. The most worrisome adverse effect of mycophenolate is bone marrow suppression, however diarrhea, nausea, and abdominal discomfort are common and for some, debilitating $(39,79)$. A newer formulation of mycophenolate sodium, Myfortic, contains MPA in a delayed release capsule that may reduce GI side effects and has shown comparable efficacy in renal and heart transplantation (41). Therapeutic monitoring of mycophenolate is possible but the efficacy and importance of monitoring has not been established (39).

Mycophenolate has demonstrated superiority in preventing ACR in several randomized trials in renal, heart and liver transplantation (80-82), however, the data has been less robust in lung transplantation. A few small nonrandomized studies demonstrated reduced episodes of acute allograft rejection with mycophenolate compared with azathioprine $(83,84)$. Two larger randomized controlled trials in lung transplant recipients failed to show a reduction in the development of ACR, infection, or BOS $(85,86)$.
These trials are summarized in Table 3.

However, recent analysis from the International Society for Heart and Lung Transplant (ISHLT) registry demonstrated that $38.1 \%$ of lung transplant recipients receiving mycophenolate mofetil, cyclosporine, and a corticosteroid experienced rejection within the first year compared with $58.1 \%$ of lung transplant recipients receiving azathioprine, cyclosporine and corticosteroid therapy $(\mathrm{P}<0.05)(78)$.

\section{Mammalian target of rapamycin (mTOR) inbibitors}

Sirolimus and everolimus are mTOR inhibitors that are structurally similar to calcineurin inhibitors and act by binding FKBP12 to form a drug-protein complex like tacrolimus. However, they instead block the mTOR instead of calcineurin, halting DNA synthesis and consequently the proliferation of $\mathrm{T}$ and $\mathrm{B}$ cells $(39,79)$. Target trough levels for sirolimus and everolimus range from 5-15 $(39,79)$ and $3-8 \mathrm{ng} / \mathrm{mL}(87,88)$, respectively. The side effect profiles for sirolimus and everolimus are similar including myelosuppression, diarrhea, mouth ulcers, hyperlipidemia, refractory edema, and most importantly impaired wound healing $(87,88)$. Likely related to the effects of mTOR inhibitors on fibroblasts, endothelial 
Table 3 Mycophenolate vs. azathioprine for lung transplant recipients

\begin{tabular}{|c|c|c|c|}
\hline Study & Population & Methodology & Outcomes \\
\hline $\begin{array}{l}\text { Palmer et al., } \\
2001 \text { (85) }\end{array}$ & 81 & $\begin{array}{l}\text { Prospective, randomized, two center, open label; } \\
\text { MMF/CsA/CS vs. AZA/CsA/CS; enrolled at time of } \\
\text { transplant, } 6 \text { months follow-up }\end{array}$ & $\begin{array}{l}\text { AR: } 63 \% \text { (MMF) vs. } 58 \% \text { (AZA), } P=0.82 \\
\text { Survival: } 86 \% \text { (MMF) vs. } 82 \% A Z A, P=0.57\end{array}$ \\
\hline
\end{tabular}

AR, acute rejection; CsA, cyclosporine; Tac, tacrolimus; MMF, mycophenolate mofetil; AZA, azathioprine; NS, non-significant and not reported in article; CS, corticosteroids; $\mathrm{AE}$, adverse events.

cells and smooth muscle cells, early studies with sirolimus reported airway anastomotic dehiscence $(89,90)$. As a result, subsequent studies have avoided mTOR inhibitors until at least 4 weeks after lung transplantation $(87,88)$. Other notable potential risks with sirolimus are venous thromboembolism (91) and drug induced pneumonitis (92). Nevertheless, mTOR inhibitors have demonstrated advantages when added to immunosuppressive regimens, including allowing the reduction of target calcineurin trough levels resulting in less nephrotoxicity $(93,94)$ and reduced risk of malignancy (95).

Although both sirolimus and everolimus have shown some efficacy in preventing rejection and supplementing immunosuppressive regimens to limit toxicity from calcineurin inhibitors, randomized trials have failed to demonstrate a clear reduction in BOS, ACR or improved survival $(87,88,96)$. There are four randomized trials that have shown mixed results using everolimus or sirolimus in terms of reducing the incidence of allograft dysfunction. Notably three of the four trials showed less CMV infection in patients on mTOR inhibitors instead of the antimetabolites $(87,88,96,97)$. Details of these studies are shown in Table 4.

\section{Antibody mediated therapies}

Immunosuppression is largely targeted at limiting cellmediated immunity, however, the dangers of antibody mediated rejection (AMR) for the allograft have become increasingly clear over time. Unfortunately, the diagnosis of AMR in lung transplant recipients remains somewhat elusive despite the recent consensus statement by the ISHLT (98). Therapy for antibody-mediated rejection involves plasmapheresis, intravenous immunoglobulin (IVIG), rituximab, bortezomib and the newer agent carfilzomib. Plasmapheresis removes circulating antibodies and hopefully donor specific antibodies (DSA) that could target the allograft. IVIG has a combination of effects resulting in apoptosis of $\mathrm{B}$ cells and inhibition of the antibody-mediated complement pathway (99). Rituximab is a monoclonal anti-CD20 antibody specific for B-cells that causes apoptosis and ultimately B-cell depletion (39). Bortezomib and carfilzomib are proteasome inhibitors that cause plasma cell apoptosis (100).

Development of de novo DSA after transplantation is associated with poorer survival and greater risk of BOS and chronic lung allograft dysfunction (101-103). Hachem et al. conducted a prospective observational study of a treatment protocol for patients with de novo DSA in the absence of allograft dysfunction, involving rituximab with IVIG versus IVIG alone. In this study both treatments similarly cleared DSA, but patients who did not clear their DSA were more likely to develop BOS $(\mathrm{P}=0.03)$ (104). Although the findings from this study suggest that aggressive multi-targeted therapy to reduce DSA after transplant is beneficial even in the absence of allograft dysfunction, larger randomized trials are needed to determine how to best approach de novo DSA. 
Table 4 mTOR inhibitors

\begin{tabular}{|c|c|c|c|}
\hline Study & Population & Methodology & Outcomes \\
\hline $\begin{array}{l}\text { Bhorade et al., } \\
2011 \text { (96) }\end{array}$ & 181 & $\begin{array}{l}\text { Prospective, multicenter, } \\
\text { randomized, open label; SIR/TAC/CS } \\
\text { vs. AZA/TAC/CS, enrolled } 90 \text { days } \\
\text { after transplant, follow-up } 36 \text { months }\end{array}$ & $\begin{array}{l}\text { No difference in AR episodes; AR: } 1 \text { year: } 39 \% \text { (SIR) vs. } 48 \% \\
\text { (AZA), } P=0.82 \text {; AR: } 3 \text {-year: } 46 \% \text { (SIR) vs. } 49 \% \text { (AZA), } P=0.57 \text {; no } \\
\text { difference in BOS at year } 1 \text { or } 3 \text {; BOS: } 1 \text { year: } 11 \%(\mathrm{SIR}) \text { vs. } 3 \% \\
\text { (AZA), } P=0.11 \text {; BOS: } 3 \text {-year: } 30 \% \text { (SIR) vs. } 22 \%(A Z A), P=0.48\end{array}$ \\
\hline $\begin{array}{l}\text { Strueber et al., } \\
2016 \text { (88) }\end{array}$ & 190 & $\begin{array}{l}\text { Prospective, randomized, single- } \\
\text { center; comparing EVE/CsA/CS vs. } \\
\text { MMF/CsA/CS; enrolled } 28 \text { days after } \\
\text { transplant with follow-up } 24 \text { months }\end{array}$ & $\begin{array}{l}\text { Results below are for ITT analysis, no difference in survival, BOS } \\
\text { incidence; high rates of cross-over and different results in per } \\
\text { protocol analysis; survival: } 2 \text {-year: } 89 \% \text { (EVE) vs. } 87 \% \text { (MMF), } \\
\mathrm{P}=0.664 \text {; BOS incidence: } 14 \% \text { (EVE) vs. } 21 \% \text { (MMF), } \mathrm{P}=0.250\end{array}$ \\
\hline
\end{tabular}

EF, efficacy failure; AR, acute rejection; CsA, cyclosporine; TAC, tacrolimus; MMF, mycophenolate mofetil; AZA, azathioprine; NS, nonsignificant and not reported in article; CS, corticosteroids; AE, adverse events; ITT, intention to treat; MPS, mycophenolate sodium; RAD, delayed-onset everolimus; mTOR, mammalian target of rapamycin.

\section{Desensitization}

The pre-transplant presence of anti-HLA antibodies in lung transplant candidates is being increasingly recognized and poses major challenges to patient selection and donor identification. The solid phase single antigen bead technology has increased the recognition and identification of anti-HLA antibodies, however there is significant controversy on how to approach patients with these antibodies (105). Studies have shown that pre-transplant sensitization with anti-HLA antibodies may be associated with decreased survival after transplantation (106). One management approach is to immediately label anti-HLA antibodies present above a certain threshold as unacceptable antigens for the patient and thus limit the available donor pool. Other approaches include desensitization prior to lung transplantation to attempt to reduce the anti-HLA antibody levels prior to transplant (107), and peri-operative desensitization at the time of transplantation (108).

Snyder and colleagues reported the outcomes of a desensitization protocol for highly sensitized pre-transplant patients with calculated panel reactive antibody (cPRA) $\geq 80 \%$. The protocol included rituximab on day 1 and 26, plasmapheresis for seven treatments over 19 days, IV solumedrol for four doses and four doses of subcutaneous bortezomib (107). Eighteen patients started the treatment and nine patients completed the treatment with early completion due to transplant. The cPRA did not change with the protocol and the median fluorescence intensity (MFI) significantly decreased only for anti-HLA antibodies in the 5,000-10,000 MFI range but not high MFI $>10,000$ or low MFI $<5,000$ anti-HLA antibodies. This desensitization protocol was not markedly successful at broadening the donor pool, and the clinical impact of these pre-transplant anti-HLA antibodies on post-transplant outcomes remains unknown (107).

Tinckam and colleagues reported their single center experience with a perioperative desensitization strategy for patients with DSA and cPRA $\geq 30 \%$ (108). To avoid the toxicities of pre-transplant desensitization before transplant and to circumvent limiting the donor pool, these patients received perioperative plasmapheresis, IVIG, 
ATG and MPA. Unsensitized patients were treated with the standard cyclosporine, azathioprine and prednisone regimen without ATG. One-year graft survival was nearly identical comparing sensitized patients who have DSA with unsensitized patients who did not have DSA (89\% vs. $86 \%, \mathrm{P}=0.47)$. This study demonstrates excellent outcomes with a perioperative desensitization approach that does not diminish the available donor pool for patients (108).

\section{The future of immunosuppression}

Survival in lung transplantation remains quite poor compared to other solid organ transplants with a median survival of 5.8 years compared to 11.9 years for heart transplantation $(18,109)$. Early mortality is largely attributable to infection and graft failure while later mortality is due to chronic lung allograft dysfunction generally resulting from allograft rejection (18). Further complicating immunosuppression in lung transplantation, is the fact that the mechanisms of immune responses in lungs vary from those observed in other organs $(110,111)$. With the exception of the small bowel, the lung is the only transplanted organ that is constantly exposed to the surrounding environment. Thus the immunosuppression required to avoid lung allograft rejection remains especially complicated. There are, however, promising avenues of active research to address these challenges.

\section{Transplant immune tolerance}

The major goal of post-transplant immunomodulation is to achieve transplant immune tolerance; a state in which the recipient's immune system no longer responds to the allograft as foreign. Transplant immune tolerance would obviate the need for immunosuppression while maintaining an intact immune system capable of fighting infection and surveilling for malignancy thus removing significant causes of morbidity and mortality after transplantation. Could this be possible?

Mixed chimerism is a state in which the donor and recipient hematopoietic cells co-exist creating donor-specific tolerance in the recipient. The first solid organ transplants to utilize mixed chimerism were performed in subjects who had undergone hematopoietic stem cell transplantation (HSCT) and subsequently developed renal failure requiring renal transplantation. These renal transplants were performed from the same HLA-identical donor, and subjects did not require subsequent immunosuppression $(112,113)$. Following the identification of this unique state of donorspecific tolerance, combined bone marrow and renal transplantation was successfully performed in subjects with multiple myeloma and associated renal failure $(114,115)$. One of the major challenges in these approaches, has been determining the least toxic conditioning regimen possible to allow for bone marrow engraftment and to achieve mixed chimerism. Such transplants were initially performed with myeloablative chemotherapy (114) but subsequently with non-myeloablative regimens (115). Regimens used for primary renal transplantation in the absence of myeloma or other malignancy, have consisted of total lymphoid irradiation and ATG (116-118), or cyclophosphamide, antiCD2 antibody, cyclosporine and thymic irradiation (119). Many subjects in these studies were able to completely stop all immunosuppressive therapy.

Applying this approach to lung transplantation is challenging as the conditioning regimens used in combined HSCT-renal transplantation must begin many days prior to solid organ transplantation thus complicating the unpredictable deceased donor availability and transplantation process that accounts for the vast majority of lung transplant surgeries. Studies performing HSCT after solid organ transplantation have been successful in non-human primates $(120,121)$. A single case report in a patient with advanced lung disease from a primary immune deficiency who underwent deceased donor lung transplantation, reports successful mixed chimerism and long-term immunosuppression withdrawal with donor-derived HSCT performed 3 months after lung transplantation (122).

While work in renal transplantation has produced remarkable advances in transplant immunology, it remains prudent to consider whether renal transplantation techniques will be easily translated to lung transplantation. Studies performed in swine models of combined heart and kidney transplantation have demonstrated that cotransplantation of a kidney is protective, and removal of the renal allograft results in acute rejection of the heart $(123,124)$. Similarly, there are numerous cases of sustained immune tolerance after withdrawal of immunosuppression in both renal and liver transplantation (125-127), while this has not been seen in lung transplantation. Additionally, the lung remains an immunologically distinct organ $(110,111)$, and in contrast to the kidney, is constantly exposed to the surrounding environment. Unfortunately, this suggests 
that the renal transplantation techniques may not be easily translated to lung transplantation.

While establishing immune tolerance is likely to be the best long-term goal for solid organ transplantation, it is likely to be many years away.

\section{Existing medications, new applications}

Bortezomib and carfilzomib are two proteasome inhibitors initially developed for the treatment of multiple myeloma. Plasma cells typically express large numbers of proteasomes which serve to ubiquinate and destroy dysfunctional or misfolded proteins. Proteasome inhibitors allow these ubiquitinated proteins to accumulate, resulting in cell death. Studies of these medications in the treatment of antibodymediated rejection are small, but suggest they may result in significant decreases in antibody levels $(128,129)$, clinical improvement (130) and return of pulmonary function to pre-AMR levels (100). One major area of controversy is the definitive diagnosis of AMR. Since its burden in lung transplant rejection is not well known, it is difficult to measure treatment efficacy (98).

Belatacept is a protein that binds the CD80 and CD86 receptors on antigen presenting cells (APC); these receptors are necessary for APC-mediated stimulation of T-cells. Belatacept blocks T-cell co-stimulation, cytokine production and T-cell proliferation. Belatacept was originally approved for use in renal transplantation but has been used as an adjunct in lung transplant recipients with acute and chronic renal failure or recipients otherwise intolerant of calcineurin inhibitors (131). Concomitant belatacept therapy has allowed for decreased dosing of calcineurin inhibitors and stabilization or improvement in renal function (132), and has been shown to maintain sufficient immunosuppression after withdrawal of CNIs (131).

\section{Conclusions}

The challenges of lung transplantation are unique, however the advances made in renal transplantation, bone marrow transplantation and transplant immunology research provide promising insights that are likely to revolutionize the way we manage lung transplantation in the future. In the meantime, ongoing investigations of available medications may help elucidate how to best prevent and treat acute and chronic allograft rejection while minimizing the risk of infection, malignancy and other toxicities of immunosuppression.

\section{Acknowledgements}

We would like to thank the Lung Transplant Project and the Boomer Esiason Foundation for their generous support of the Columbia University Lung Transplant program.

\section{Footnote}

Conflicts of Interest: The authors have no conflicts of interest to declare.

\section{References}

1. Linden PK. History of solid organ transplantation and organ donation. Crit Care Clin 2009;25:165-84, ix.

2. Starzl TE, Marchioro TL, Waddell WR. The Reversal of Rejection in Human Renal Homografts with Subsequent Development of Homograft Tolerance. Surg Gynecol Obstet 1963;117:385-95.

3. Murray JE, Merrill JP, Harrison JH, et al.

Prolonged survival of human-kidney homografts by immunosuppressive drug therapy. $\mathrm{N}$ Engl J Med 1963;268:1315-23.

4. Blumenstock DA, Lewis C. The first transplantation of the lung in a human revisited. Ann Thorac Surg 1993;56:14234; discussion 1424-5.

5. Reitz BA, Wallwork JL, Hunt SA, et al. Heart-lung transplantation: successful therapy for patients with pulmonary vascular disease. N Engl J Med 1982;306:557-64.

6. Cooper JD, Pearson FG, Patterson GA, et al. Technique of successful lung transplantation in humans. J Thorac Cardiovasc Surg 1987;93:173-81.

7. Hosenpud JD, Bennett LE, Keck BM, et al. The Registry of the International Society for Heart and Lung Transplantation: sixteenth official report--1999. J Heart Lung Transplant 1999;18:611-26.

8. Trulock EP. Management of lung transplant rejection. Chest 1993;103:1566-76.

9. Karam S, Wali RK. Current State of Immunosuppression: Past, Present, and Future. Crit Rev Eukaryot Gene Expr 2015;25:113-34.

10. Palmer SM, Miralles AP, Lawrence CM, et al. Rabbit antithymocyte globulin decreases acute rejection after lung transplantation: results of a randomized, prospective study. Chest 1999;116:127-33.

11. Brock MV, Borja MC, Ferber L, et al. Induction therapy in lung transplantation: a prospective, controlled clinical trial comparing OKT3, anti-thymocyte globulin, and daclizumab. J Heart Lung Transplant 2001;20:1282-90. 
12. Beaufigeau M, Dumesnil D, Carrier M, et al. Seven-year experience with rabbit antithymocyte globulin after cardiac transplantation at the Montreal Heart Institute. Transplant Proc 1997;29:10S-2S.

13. Szczech LA, Berlin JA, Feldman HI. The effect of antilymphocyte induction therapy on renal allograft survival. A meta-analysis of individual patient-level data. Anti-Lymphocyte Antibody Induction Therapy Study Group. Ann Intern Med 1998;128:817-26.

14. Rosenberg PB, Vriesendorp AE, Drazner MH, et al. Induction therapy with basiliximab allows delayed initiation of cyclosporine and preserves renal function after cardiac transplantation. J Heart Lung Transplant 2005;24:1327-31.

15. Opelz G, Dohler B. Lymphomas after solid organ transplantation: a collaborative transplant study report. Am J Transplant 2004;4:222-30.

16. Mazimba S, Tallaj JA, George JF, et al. Infection and rejection risk after cardiac transplantation with induction vs. no induction: a multi-institutional study. Clin Transplant 2014;28:946-52.

17. Christie JD, Edwards LB, Kucheryavaya AY, et al. The Registry of the International Society for Heart and Lung Transplantation: 29th adult lung and heart-lung transplant report-2012. J Heart Lung Transplant 2012;31:1073-86.

18. Yusen RD, Edwards LB, Dipchand AI, et al. The Registry of the International Society for Heart and Lung Transplantation: Thirty-third Adult Lung and HeartLung Transplant Report-2016; Focus Theme: Primary Diagnostic Indications for Transplant. J Heart Lung Transplant 2016;35:1170-84.

19. Chambers DC, Yusen RD, Cherikh WS, et al. The Registry of the International Society for Heart and Lung Transplantation: Thirty-fourth Adult Lung And HeartLung Transplantation Report-2017; Focus Theme: Allograft ischemic time. J Heart Lung Transplant 2017;36:1047-59.

20. Penninga L, Moller CH, Penninga EI, et al. Antibody induction therapy for lung transplant recipients. Cochrane Database Syst Rev 2013:CD008927.

21. Furuya Y, Jayarajan SN, Taghavi S, et al. The Impact of Alemtuzumab and Basiliximab Induction on Patient Survival and Time to Bronchiolitis Obliterans Syndrome in Double Lung Transplantation Recipients. Am J Transplant 2016;16:2334-41.

22. Knoop C, Haverich A, Fischer S. Immunosuppressive therapy after human lung transplantation. Eur Respir J 2004;23:159-71.
23. Schnetzler B, Leger P, Volp A, et al. A prospective randomized controlled study on the efficacy and tolerance of two antilymphocytic globulins in the prevention of rejection in first-heart transplant recipients. Transpl Int 2002;15:317-25.

24. Regan JF, Campbell K, Van Smith L, et al. Sensitization following Thymoglobulin and Atgam rejection therapy as determined with a rapid enzyme-linked immunosorbent assay. US Thymoglobulin Multi-Center Study Group. Transpl Immunol 1999;7:115-21.

25. McManigle W, Pavlisko EN, Martinu T. Acute cellular and antibody-mediated allograft rejection. Semin Respir Crit Care Med 2013;34:320-35.

26. Sweet SC. Induction therapy in lung transplantation. Transpl Int 2013;26:696-703.

27. Jaksch P, Ankersmit J, Scheed A, et al. Alemtuzumab in lung transplantation: an open-label, randomized, prospective single center study. Am J Transplant 2014;14:1839-45.

28. Shyu S, Dew MA, Pilewski JM, et al. Five-year outcomes with alemtuzumab induction after lung transplantation. J Heart Lung Transplant 2011;30:743-54.

29. Magliocca JF, Knechtle SJ. The evolving role of alemtuzumab (Campath-1H) for immunosuppressive therapy in organ transplantation. Transpl Int 2006;19:705-14.

30. Whited LK, Latran MJ, Hashmi ZA, et al. Evaluation of Alemtuzumab Versus Basiliximab Induction: A Retrospective Cohort Study in Lung Transplant Recipients. Transplantation 2015;99:2190-5.

31. Swarup R, Allenspach LL, Nemeh HW, et al. Timing of basiliximab induction and development of acute rejection in lung transplant patients. J Heart Lung Transplant 2011;30:1228-35.

32. Grundy N, Simmonds J, Dawkins H, et al. Preimplantation basiliximab reduces incidence of early acute rejection in pediatric heart transplantation. J Heart Lung Transplant 2009;28:1279-84.

33. Hartwig MG, Snyder LD, Appel JZ 3rd, et al. Rabbit anti-thymocyte globulin induction therapy does not prolong survival after lung transplantation. J Heart Lung Transplant 2008;27:547-53.

34. Garrity ER, Jr., Villanueva J, Bhorade SM, et al. Low rate of acute lung allograft rejection after the use of daclizumab, an interleukin 2 receptor antibody. Transplantation 2001;71:773-7.

35. Borro JM, De la Torre M, Miguelez C, et al. Comparative study of basiliximab treatment in lung transplantation. 
Transplant Proc 2005;37:3996-8.

36. van Loenhout KC, Groves SC, Galazka M, et al. Early outcomes using alemtuzumab induction in lung transplantation. Interact Cardiovasc Thorac Surg 2010;10:190-4.

37. Whitson BA, Lehman A, Wehr A, et al. To induce or not to induce: a 21st century evaluation of lung transplant immunosuppression's effect on survival. Clin Transplant 2014;28:450-61.

38. McCurry KR, Iacono A, Zeevi A, et al. Early outcomes in human lung transplantation with Thymoglobulin or Campath-1H for recipient pretreatment followed by posttransplant tacrolimus near-monotherapy. J Thorac Cardiovasc Surg 2005;130:528-37.

39. Scheffert JL, Raza K. Immunosuppression in lung transplantation. J Thorac Dis 2014;6:1039-53.

40. Hopkins PM, McNeil K. Evidence for immunosuppression in lung transplantation. Curr Opin Organ Transplant 2008; 13:477-83.

41. Floreth T, Bhorade SM. Current trends in immunosuppression for lung transplantation. Semin Respir Crit Care Med 2010;31:172-8.

42. Valapour M, Skeans MA, Smith JM, et al. OPTN/SRTR 2015 Annual Data Report: Lung. Am J Transplant 2017;17 Suppl 1:357-424.

43. Yusen RD, Edwards LB, Kucheryavaya AY, et al. The Registry of the International Society for Heart and Lung Transplantation: Thirty-second Official Adult Lung and Heart-Lung Transplantation Report--2015; Focus Theme: Early Graft Failure. J Heart Lung Transplant 2015;34:1264-77.

44. Parada MT, Alba A, Sepulveda C. Early and late infections in lung transplantation patients. Transplant Proc 2010;42:333-5.

45. Arcasoy SM, Wilt J. Medical complications after lung transplantation. Semin Respir Crit Care Med 2006;27:508-20.

46. Rhen T, Cidlowski JA. Antiinflammatory action of glucocorticoids--new mechanisms for old drugs. N Engl J Med 2005;353:1711-23.

47. Boumpas DT, Chrousos GP, Wilder RL, et al. Glucocorticoid therapy for immune-mediated diseases: basic and clinical correlates. Ann Intern Med 1993;119:1198-208.

48. Hoes JN, Jacobs JW, Verstappen SM, et al. Adverse events of low- to medium-dose oral glucocorticoids in inflammatory diseases: a meta-analysis. Ann Rheum Dis 2009;68:1833-8.
49. Curtis JR, Westfall AO, Allison J, et al. Population-based assessment of adverse events associated with long-term glucocorticoid use. Arthritis Rheum 2006;55:420-6.

50. W J Bijlsma J, Buttgereit F. Adverse events of glucocorticoids during treatment of rheumatoid arthritis: lessons from cohort and registry studies. Rheumatology (Oxford) 2016;55:ii3-ii5.

51. Shitrit D, Bendayan D, Sulkes J, et al. Successful steroid withdrawal in lung transplant recipients: result of a pilot study. Respir Med 2005;99:596-601.

52. Borro JM, Sole A, De la Torre M, et al. Steroid withdrawal in lung transplant recipients. Transplant Proc 2005;37:3991-3.

53. Schreiber SL, Crabtree GR. The mechanism of action of cyclosporin A and FK506. Immunol Today 1992;13:136-42.

54. Wiederrecht G, Lam E, Hung S, et al. The mechanism of action of FK-506 and cyclosporin A. Ann N Y Acad Sci 1993;696:9-19.

55. Mahalati K, Belitsky P, West K, et al. Approaching the therapeutic window for cyclosporine in kidney transplantation: a prospective study. J Am Soc Nephrol 2001;12:828-33.

56. Grevel J, Welsh MS, Kahan BD. Cyclosporine monitoring in renal transplantation: area under the curve monitoring is superior to trough-level monitoring. Ther Drug Monit 1989;11:246-8.

57. Morton JM, Aboyoun CL, Malouf MA, et al. Enhanced clinical utility of de novo cyclosporine C2 monitoring after lung transplantation. J Heart Lung Transplant 2004;23:1035-9.

58. Trull A, Steel L, Sharples L, et al. Randomized, trough blood cyclosporine concentration-controlled trial to compare the pharmacodynamics of Sandimmune and Neoral in de novo lung transplant recipients. Ther Drug Monit 1999;21:17-26.

59. Flechner SM, Kobashigawa J, Klintmalm G. Calcineurin inhibitor-sparing regimens in solid organ transplantation: focus on improving renal function and nephrotoxicity. Clin Transplant 2008;22:1-15.

60. Gijtenbeek JM, van den Bent MJ, Vecht CJ. Cyclosporine neurotoxicity: a review. J Neurol 1999;246:339-46.

61. Fan Y, Xiao YB, Weng YG. Tacrolimus versus cyclosporine for adult lung transplant recipients: a meta-analysis. Transplant Proc 2009;41:1821-4.

62. Heisel O, Heisel R, Balshaw R, et al. New onset diabetes mellitus in patients receiving calcineurin inhibitors: $\mathrm{a}$ systematic review and meta-analysis. Am J Transplant 2004;4:583-95. 
63. Moore R, Hernandez D, Valantine H. Calcineurin inhibitors and post-transplant hyperlipidaemias. Drug Saf 2001;24:755-66.

64. Muduma G, Saunders R, Odeyemi I, et al. Systematic Review and Meta-Analysis of Tacrolimus versus Ciclosporin as Primary Immunosuppression After Liver Transplant. PLoS One 2016;11:e0160421.

65. Penninga L, Moller CH, Gustafsson F, et al. Tacrolimus versus cyclosporine as primary immunosuppression after heart transplantation: systematic review with meta-analyses and trial sequential analyses of randomised trials. Eur J Clin Pharmacol 2010;66:1177-87.

66. Fung JJ. Tacrolimus and transplantation: a decade in review. Transplantation 2004;77:S41-3.

67. Plosker GL, Foster RH. Tacrolimus: a further update of its pharmacology and therapeutic use in the management of organ transplantation. Drugs 2000;59:323-89.

68. Knoop C, Thiry P, Saint-Marcoux F, et al. Tacrolimus pharmacokinetics and dose monitoring after lung transplantation for cystic fibrosis and other conditions. Am J Transplant 2005;5:1477-82.

69. Ragette R, Kamler M, Weinreich G, et al. Tacrolimus pharmacokinetics in lung transplantation: new strategies for monitoring. J Heart Lung Transplant 2005;24:1315-9.

70. Randomised trial comparing tacrolimus (FK506) and cyclosporin in prevention of liver allograft rejection. European FK506 Multicentre Liver Study Group. Lancet 1994;344:423-8.

71. Group USMFLS. A comparison of tacrolimus (FK 506) and cyclosporine for immunosuppression in liver transplantation. N Engl J Med 1994;331:1110-5.

72. Keenan RJ, Konishi H, Kawai A, et al. Clinical trial of tacrolimus versus cyclosporine in lung transplantation. Ann Thorac Surg 1995;60:580-4; discussion 584-5.

73. Zuckermann A, Reichenspurner H, Birsan T, et al. Cyclosporine A versus tacrolimus in combination with mycophenolate mofetil and steroids as primary immunosuppression after lung transplantation: one-year results of a 2-center prospective randomized trial. J Thorac Cardiovasc Surg 2003;125:891-900.

74. Zuckermann A, Reichenspurner H. Long Term Follow up of a prospective randomized trial comparing tacrolimus versus cyclosporine in combination with MMF after Lung Transplantation. The Journal of Heart and Lung Transplantation 2003;22:S76-S7.

75. Hachem RR, Yusen RD, Chakinala MM, et al. A randomized controlled trial of tacrolimus versus cyclosporine after lung transplantation. J Heart Lung
Transplant 2007;26:1012-8.

76. Treede H, Glanville AR, Klepetko W, et al. Tacrolimus and cyclosporine have differential effects on the risk of development of bronchiolitis obliterans syndrome: results of a prospective, randomized international trial in lung transplantation. J Heart Lung Transplant 2012;31:797-804.

77. Treede H, Klepetko W, Reichenspurner H, et al. Tacrolimus versus cyclosporine after lung transplantation: a prospective, open, randomized two-center trial comparing two different immunosuppressive protocols. J Heart Lung Transplant 2001;20:511-7.

78. Madoff SD, Kaye J, Newman JS. Postoperative Foot and Ankle MR Imaging. Magn Reson Imaging Clin N Am 2017;25:195-209.

79. Taylor AL, Watson CJ, Bradley JA. Immunosuppressive agents in solid organ transplantation: Mechanisms of action and therapeutic efficacy. Crit Rev Oncol Hematol 2005;56:23-46.

80. A blinded, randomized clinical trial of mycophenolate mofetil for the prevention of acute rejection in cadaveric renal transplantation. The Tricontinental Mycophenolate Mofetil Renal Transplantation Study Group. Transplantation 1996;61:1029-37.

81. Wiesner R, Rabkin J, Klintmalm G, et al. A randomized double-blind comparative study of mycophenolate mofetil and azathioprine in combination with cyclosporine and corticosteroids in primary liver transplant recipients. Liver Transpl 2001;7:442-50.

82. Kobashigawa J, Miller L, Renlund D, et al. A randomized active-controlled trial of mycophenolate mofetil in heart transplant recipients. Mycophenolate Mofetil Investigators. Transplantation 1998;66:507-15.

83. Zuckermann A, Klepetko W, Birsan T, et al. Comparison between mycophenolate mofetil- and azathioprine-based immunosuppressions in clinical lung transplantation. J Heart Lung Transplant 1999;18:432-40.

84. Ross DJ, Waters PF, Levine M, et al. Mycophenolate mofetil versus azathioprine immunosuppressive regimens after lung transplantation: preliminary experience. J Heart Lung Transplant 1998;17:768-74.

85. Palmer SM, Baz MA, Sanders L, et al. Results of a randomized, prospective, multicenter trial of mycophenolate mofetil versus azathioprine in the prevention of acute lung allograft rejection. Transplantation 2001;71:1772-6.

86. McNeil K, Glanville AR, Wahlers T, et al. Comparison of mycophenolate mofetil and azathioprine for prevention of bronchiolitis obliterans syndrome in de novo lung 
transplant recipients. Transplantation 2006;81:998-1003.

87. Glanville AR, Aboyoun C, Klepetko W, et al. Threeyear results of an investigator-driven multicenter, international, randomized open-label de novo trial to prevent BOS after lung transplantation. J Heart Lung Transplant 2015;34:16-25.

88. Strueber M, Warnecke G, Fuge J, et al. Everolimus Versus Mycophenolate Mofetil De Novo After Lung Transplantation: A Prospective, Randomized, Open-Label Trial. Am J Transplant 2016;16:3171-80.

89. Groetzner J, Kur F, Spelsberg F, et al. Airway anastomosis complications in de novo lung transplantation with sirolimus-based immunosuppression. J Heart Lung Transplant 2004;23:632-8.

90. King-Biggs MB, Dunitz JM, Park SJ, et al. Airway anastomotic dehiscence associated with use of sirolimus immediately after lung transplantation. Transplantation 2003;75:1437-43.

91. Ahya VN, McShane PJ, Baz MA, et al. Increased risk of venous thromboembolism with a sirolimus-based immunosuppression regimen in lung transplantation. J Heart Lung Transplant 2011;30:175-81.

92. McWilliams TJ, Levvey BJ, Russell PA, et al. Interstitial pneumonitis associated with sirolimus: a dilemma for lung transplantation. J Heart Lung Transplant 2003;22:210-3.

93. Gullestad L, Iversen M, Mortensen SA, et al. Everolimus with reduced calcineurin inhibitor in thoracic transplant recipients with renal dysfunction: a multicenter, randomized trial. Transplantation 2010;89:864-72.

94. Shitrit D, Rahamimov R, Gidon S, et al. Use of sirolimus and low-dose calcineurin inhibitor in lung transplant recipients with renal impairment: results of a controlled pilot study. Kidney Int 2005;67:1471-5.

95. Knoll GA, Kokolo MB, Mallick R, et al. Effect of sirolimus on malignancy and survival after kidney transplantation: systematic review and meta-analysis of individual patient data. BMJ 2014;349:g6679.

96. Bhorade S, Ahya VN, Baz MA, et al. Comparison of sirolimus with azathioprine in a tacrolimus-based immunosuppressive regimen in lung transplantation. Am J Respir Crit Care Med 2011;183:379-87.

97. Snell GI, Valentine VG, Vitulo P, et al. Everolimus versus azathioprine in maintenance lung transplant recipients: an international, randomized, double-blind clinical trial. Am J Transplant 2006;6:169-77.

98. Levine DJ, Glanville AR, Aboyoun C, et al. Antibodymediated rejection of the lung: A consensus report of the International Society for Heart and Lung Transplantation.
J Heart Lung Transplant 2016;35:397-406.

99. Gelfand EW. Intravenous immune globulin in autoimmune and inflammatory diseases. N Engl J Med 2012;367:2015-25.

100.Ensor CR, Yousem SA, Marrari M, et al. Proteasome Inhibitor Carfilzomib-Based Therapy for AntibodyMediated Rejection of the Pulmonary Allograft: Use and Short-Term Findings. Am J Transplant 2017;17:1380-8.

101.Safavi S, Robinson DR, Soresi S, et al. De novo donor HLA-specific antibodies predict development of bronchiolitis obliterans syndrome after lung transplantation. J Heart Lung Transplant 2014;33:1273-81.

102. Morrell MR, Pilewski JM, Gries CJ, et al. De novo donorspecific HLA antibodies are associated with early and high-grade bronchiolitis obliterans syndrome and death after lung transplantation. J Heart Lung Transplant 2014;33:1288-94.

103. Tikkanen JM, Singer LG, Kim SJ, et al. De Novo DQ Donor-Specific Antibodies Are Associated with Chronic Lung Allograft Dysfunction after Lung Transplantation. Am J Respir Crit Care Med 2016;194:596-606.

104.Hachem RR, Yusen RD, Meyers BF, et al. Anti-human leukocyte antigen antibodies and preemptive antibodydirected therapy after lung transplantation. J Heart Lung Transplant 2010;29:973-80.

105.Hachem RR, Reinsmoen NL. What is the definition of a clinically relevant donor HLA-specific antibody (DSA)? Am J Transplant 2015;15:299-300.

106. Smith JD, Ibrahim MW, Newell H, et al. Pre-transplant donor HLA-specific antibodies: characteristics causing detrimental effects on survival after lung transplantation. J Heart Lung Transplant 2014;33:1074-82.

107. Snyder LD, Gray AL, Reynolds JM, et al. Antibody desensitization therapy in highly sensitized lung transplant candidates. Am J Transplant 2014;14:849-56.

108. Tinckam KJ, Keshavjee S, Chaparro C, et al. Survival in sensitized lung transplant recipients with perioperative desensitization. Am J Transplant 2015;15:417-26.

109. Lund LH, Edwards LB, Dipchand AI, et al. The Registry of the International Society for Heart and Lung Transplantation: Thirty-third Adult Heart Transplantation Report-2016; Focus Theme: Primary Diagnostic Indications for Transplant. J Heart Lung Transplant 2016;35:1158-69.

110. Gelman AE, Li W, Richardson SB, et al. Cutting edge: Acute lung allograft rejection is independent of secondary lymphoid organs. J Immunol 2009;182:3969-73.

111.Li W, Bribriesco AC, Nava RG, et al. Lung transplant 
acceptance is facilitated by early events in the graft and is associated with lymphoid neogenesis. Mucosal Immunol 2012;5:544-54.

112. Sayegh MH, Fine NA, Smith JL, et al. Immunologic tolerance to renal allografts after bone marrow transplants from the same donors. Ann Intern Med 1991;114:954-5.

113.Helg C, Chapuis B, Bolle JF, et al. Renal transplantation without immunosuppression in a host with tolerance induced by allogeneic bone marrow transplantation. Transplantation 1994;58:1420-2.

114. Spitzer TR, Sykes M, Tolkoff-Rubin N, et al. Long-term follow-up of recipients of combined human leukocyte antigen-matched bone marrow and kidney transplantation for multiple myeloma with end-stage renal disease. Transplantation 2011;91:672-6.

115. Fudaba Y, Spitzer TR, Shaffer J, et al. Myeloma responses and tolerance following combined kidney and nonmyeloablative marrow transplantation: in vivo and in vitro analyses. Am J Transplant 2006;6:2121-33.

116. Scandling JD, Busque S, Shizuru JA, et al. Chimerism, graft survival, and withdrawal of immunosuppressive drugs in HLA matched and mismatched patients after living donor kidney and hematopoietic cell transplantation. Am J Transplant 2015;15:695-704.

117. Scandling JD, Busque S, Shizuru JA, et al. Induced immune tolerance for kidney transplantation. N Engl J Med 2011;365:1359-60.

118. Scandling JD, Busque S, Dejbakhsh-Jones S, et al. Tolerance and chimerism after renal and hematopoieticcell transplantation. N Engl J Med 2008;358:362-8.

119. Kawai T, Cosimi AB, Spitzer TR, et al. HLAmismatched renal transplantation without maintenance immunosuppression. N Engl J Med 2008;358:353-61.

120. Yamada Y, Boskovic S, Aoyama A, et al. Overcoming memory T-cell responses for induction of delayed tolerance in nonhuman primates. Am J Transplant 2012;12:330-40.

121. Koyama I, Nadazdin O, Boskovic S, et al. Depletion of CD8 memory $\mathrm{T}$ cells for induction of tolerance of a previously transplanted kidney allograft. Am J Transplant 2007;7:1055-61.

Cite this article as: Benvenuto LJ, Anderson MR, Arcasoy SM. New frontiers in immunosuppression. J Thorac Dis 2018;10(5):3141-3155. doi: 10.21037/jtd.2018.04.79
122. Szabolcs P, Buckley RH, Davis RD, et al. Tolerance and immunity after sequential lung and bone marrow transplantation from an unrelated cadaveric donor. J Allergy Clin Immunol 2015;135:567-70.

123. Madariaga ML, Michel SG, Tasaki M, et al. Induction of cardiac allograft tolerance across a full MHC barrier in miniature swine by donor kidney cotransplantation. Am J Transplant 2013;13:2558-66.

124. Mezrich JD, Benjamin LC, Sachs JA, et al. Role of the thymus and kidney graft in the maintenance of tolerance to heart grafts in miniature swine. Transplantation 2005;79:1663-73.

125.Liu XQ, Hu ZQ, Pei YF, et al. Clinical operational tolerance in liver transplantation: state-of-the-art perspective and future prospects. Hepatobiliary Pancreat Dis Int 2013;12:12-33.

126. Brouard S, Pallier A, Renaudin K, et al. The natural history of clinical operational tolerance after kidney transplantation through twenty-seven cases. Am J Transplant 2012;12:3296-307.

127. Ramos HC, Reyes J, Abu-Elmagd K, et al. Weaning of immunosuppression in long-term liver transplant recipients. Transplantation 1995;59:212-7.

128. Neumann J, Tarrasconi H, Bortolotto A, et al. Acute humoral rejection in a lung recipient: reversion with bortezomib. Transplantation 2010;89:125-6.

129. Stuckey LJ, Kamoun M, Chan KM. Lung transplantation across donor-specific anti-human leukocyte antigen antibodies: utility of bortezomib therapy in early graft dysfunction. Ann Pharmacother 2012;46:e2.

130. Baum C, Reichenspurner H, Deuse T. Bortezomib rescue therapy in a patient with recurrent antibody-mediated rejection after lung transplantation. J Heart Lung Transplant 2013;32:1270-1.

131.Iasella CJ, Winstead RJ, Moore CA, et al. Maintenance Belatacept-Based Immunosuppression in Lung Transplantation Recipients Who Failed Calcineurin Inhibitors. Transplantation 2018;102:171-7.

132. Timofte I, Terrin M, Barr E, et al. Belatacept for renal rescue in lung transplant patients. Transpl Int 2016;29:453-63. 